\title{
Effect of olive oil on early and late events of colon carcinogenesis in rats: modulation of arachidonic acid metabolism and local prostaglandin $\mathrm{E}_{2}$ synthesis
} R Bartolí, F Fernández-Bañares, E Navarro, E Castellà, J Mañé, M Alvarez, C Pastor,
E Cabré, M A Gassull

\begin{abstract}
Background-Animal model studies have shown that the colon tumour promoting effect of dietary fat depends not only on the amount but on its fatty acid composition. With respect to this, the effect of $n 9$ fatty acids, present in olive oil, on colon carcinogenesis has been scarcely investigated.
\end{abstract}

Aims-To assess the effect of an $\mathbf{n} 9$ fat diet on precancer events, carcinoma development, and changes in mucosal fatty acid composition and prostaglandin $(\mathbf{P G}) \mathrm{E}_{2}$ formation in male Sprague-Dawley rats with azoxymethane induced colon cancer. Methods-Rats were divided into three groups to receive isocaloric diets (5\% of the energy as fat) rich in $n 9, n 3$, or $n 6$ fat, and were administered azoxymethane subcutaneously once a week for 11 weeks at a dose rate of $7.4 \mathrm{mg} / \mathrm{kg}$ body weight. Vehicle treated groups received an equal volume of normal saline. Groups of animals were colectomised at weeks 12 and 19 after the first dose of azoxymethane or saline. Mucosal fatty acids were assessed at 12 and 19 weeks. Aberrant crypt foci and the in vivo intracolonic release of $\mathrm{PGE}_{2}$ were assessed at week 12, and tumour formation at week 19.

Results-Rats on the $\mathbf{n} 6$ diet were found to have colonic aberrant crypt foci and adenocarcinomas more often than those consuming either the $\mathrm{n} 9$ or $\mathrm{n} 3$ diet. There were no differences between the rats on the $n 9$ and $n 3$ diets. On the other hand, administration of both $\mathrm{n} 9$ and $\mathrm{n} 3$ diets was associated with a decrease in mucosal arachidonate concentrations as compared with the n6 diet. Carcinogen treatment induced an appreciable increase in $\mathrm{PGE}_{2}$ formation in rats fed the $\mathrm{n} 6$ diet, but not in those fed the $\mathrm{n} 3$ and $\mathrm{n} 9$ diets.

Conclusions-Dietary olive oil prevented the development of aberrant crypt foci and colon carcinomas in rats, suggesting that olive oil may have chemopreventive activity against colon carcinogenesis. These effects may be partly due to modulation of arachidonic acid metabolism and local PGE 2 synthesis.

(Gut 2000;46:191-199)

Keywords: olive oil; fish oil; azoxymethane; carcinogenesis; fatty acids; prostaglandin $\mathrm{E}_{2}$
Dietary fat has received considerable attention as a possible risk factor in the aetiology of colon cancer. Epidemiological studies have indicated that the amount of dietary fat is related to colon cancer incidence. ${ }^{12}$ Animal studies have also consistently shown a tumour promoting effect of high fat diets $(20 \% v 5 \%$ dietary fat $) .{ }^{3}$ On the other hand, similar studies have shown that the colon tumour promoting effect in animals depends not only on the amount of fat but also on its fatty acid composition. High fat corn oil based diets (23.5\% n6 fatty acids) favour colon carcinogenesis, particularly in its postinitiation or promotional phase, ${ }^{45}$ whereas feeding high fat diets rich in fish oil $(23.5 \% \mathrm{n} 3$ fatty acids) decreases colon tumour incidence in both the initiation and post-initiation phase. ${ }^{5}$ The effect of olive oil on colon carcinogenesis has been scarcely studied. However, in one study, high fat diets containing olive oil $(23.5 \%$ $\mathrm{n} 9$ fatty acids) have also been reported to have low colon tumour promoting effects. ${ }^{6}$

Most studies evaluating the tumour promoting effect of fat in rats have used $20 \%$ (about $5 \%$ of calories) fat diets, as this fat derived energy intake would be equivalent to that of humans in Western countries. However, 4-5\% of fat (about $12 \%$ of calories) is the normal recommended amount of fat for long term feeding studies in rats. ${ }^{7}$ Macronutrient and energy distribution of the diet is very different between humans and rats. Daily energy intake in the rat is about $1672 \mathrm{~kJ} / \mathrm{kg}$ body weight, whereas in humans it is about $125-146 \mathrm{~kJ} / \mathrm{kg}$ body weight. Although $20 \%$ high fat diets have been very useful for investigating the tumour promoting effect of fat in rats, the $5 \%$ level seems to be more reasonable for assessing the preventive effect of a normal content fat diet. In fact, it is not well known whether or not the effects of different fatty acid composition of diets on colon carcinogenesis persist when diets with a normal amount of fat ( $5 \%$ dietary fat for rats) are administered. With respect to this, it has been shown that $5 \%$ fat diets rich in eicosapentaenoic acid (EPA; n3 fatty acid) or stearic acid (saturated fatty acid) have an inhibitory effect on colon carcinogenesis as compared with $5 \%$ fat diets rich in linoleic acid (n6 fatty acid). ${ }^{8}$

Abbreviations used in this paper: EPA, eicosapentaenoic acid; ACF, aberrant crypt foci; $\mathrm{PGE}_{2}$, prostaglandin $\mathrm{E}_{2}$; HPLC, high performance liquid chromatography; ARA:EPA ratio, arachidonic acid to EPA ratio. 
To our knowledge, the preventive effect of normal containing $5 \%$ fat diets rich in olive oil on rat colonic carcinogenesis has not been studied. This may be relevant as oleic acid (the major fatty acid in olive oil) is the main fat component of the Mediterranean diet, and olive oil has been found to be protective against oxidative stress and carcinogenesis. ${ }^{10}{ }^{11} \mathrm{~A}$ recent epidemiological study performed in France suggests that a low intake of oleic acid may increase the risk of left colon cancer. ${ }^{12}$ Furthermore, another recent study suggests that high consumption of monounsaturated fats, mostly derived from olive oil, would be associated with a significant decrease in the risk of colorectal cancer with wild type Ki-ras genotype. ${ }^{13}$ Therefore the present study was designed to examine the effect of a 5\% fat olive oil based diet, in comparison with isolipidic fish oil and safflower oil based diets, on the early and late phases of azoxymethane induced colon carcinogenesis. The effect of the different types of fat on both mucosal fatty acid composition and local prostaglandin $\mathrm{E}_{2}\left(\mathrm{PGE}_{2}\right)$ production were also assessed.

\section{Materials and methods}

RATS AND DIETS

Four week old male Sprague-Dawley rats (about 90-100 g body weight) were purchased from B\&K Universal, Barcelona, Spain. The animals were housed two to a cage in wire drop-bottom cages, to minimise coprophagia and to prevent the consumption of bedding, under controlled conditions of a 16 hour/8 hour light/dark cycle, $50 \%$ humidity, and $21^{\circ} \mathrm{C}$ temperature. Animals were fed ad libitum. The food cups, especially adapted for powdered diets, were replenished with fresh diet every day.

The experimental diets were prepared by Scientific Hospital Supplies (SHS) International Limited, Liverpool, UK. They were unflavoured powdered diets containing the following calculated amounts (per $100 \mathrm{~g}$ ): fat, $5 \mathrm{~g}$; protein, $20 \mathrm{~g}$; carbohydrate, $64 \mathrm{~g}$; fibre, $8 \mathrm{~g}$; vitamins, $90 \mathrm{mg}$; minerals, $2 \mathrm{~g}$; trace elements, $74 \mathrm{mg}$. The energy value for the three diets was 16.1 MJ/kg. They were made up in a defatted basic diet safflower oil (n6 diet), Ropufa ‘ '30' n3 EPA oil (n3 diet), or olive oil (n9 diet). The Ropufa ‘ 30 ' n3 EPA oil was from Roche, Basel, Switzerland, and the safflower and olive oils were supplied by Alembic Products Limited, Chester, UK. Table 1 shows the fatty acid composition of the diets as measured by gas liquid chromatography (see below). The major difference between the three diets is that the $n 6$ diet was rich in linoleic acid, the $n 3$ diet was rich in EPA and docosahexaenoic acids, and the $\mathrm{n} 9$ diet was rich in oleic acid. The diets were packaged in hermetically sealed containers with nitrogen gas and stored in a refrigerator before use.

During the 15th week of the experiment (age of animals 20 weeks), food consumption was assessed in four rats selected at random from each dietary group. Each animal was housed separately. After acclimatisation for four days, the daily dietary consumption was determined over the subsequent seven days.
Table 1 Fatty acid composition of experimental diets (mean of at least four samples of powdered diet)

\begin{tabular}{llcc}
\hline Fatty acid & $n 6$ diet (\%) & $n 3$ diet (\%) & $n 9$ diet (\%) \\
\hline $14: 0$ & 0.72 & 6.68 & 1.05 \\
$16: 0$ & 9.85 & 19.85 & 19.09 \\
$16: 1 \mathrm{n} 7$ & 0.18 & 7.70 & 0.79 \\
$18: 0$ & 5.23 & 4.26 & 7.63 \\
$18: 1 \mathrm{n} 9$ & 19.28 & 13.41 & 56.04 \\
$18: 1 \mathrm{n} 7$ & $\mathrm{ND}$ & 3.01 & 0.49 \\
$18: 2 \mathrm{n} 6$ & 59.12 & 12.11 & 8.46 \\
$18: 3 \mathrm{n} 6$ & 0.33 & 0.26 & 0.88 \\
$18: 3 \mathrm{n} 3$ & 0.50 & 1.02 & 0.60 \\
$20: 4 \mathrm{n} 6$ & 1.09 & 1.14 & $\mathrm{ND}$ \\
$20: 5 \mathrm{n} 3$ & $\mathrm{ND}$ & 16.91 & $\mathrm{ND}$ \\
$24: 0$ & $\mathrm{ND}$ & 0.87 & $\mathrm{ND}$ \\
$24: 1 \mathrm{n} 9$ & 0.32 & 0.40 & 0.96 \\
$22: 5 \mathrm{n} 6$ & $\mathrm{ND}$ & 0.28 & $\mathrm{ND}$ \\
$22: 5 \mathrm{n} 3$ & $\mathrm{ND}$ & 1.70 & ND \\
$22: 6 \mathrm{n} 3$ & $\mathrm{ND}$ & 8.08 & ND \\
\hline
\end{tabular}

ND, not detected.

The study was conducted according to the Guide for the Care and Use of Laboratory Animals, and was approved by the research and ethics committee of our hospital.

\section{EXPERIMENTAL DESIGN}

A total of 108 rats were randomly assigned to three dietary groups of 36 animals each (n6, $\mathrm{n} 3$, and $\mathrm{n} 9$ diets). After a one week period of adaptation, each dietary group was divided into carcinogen treated (18 rats) and vehicle treated (18 rats) subgroups. Animals intended for carcinogen treatment were given azoxymethane (Sigma Aldrich, Madrid, Spain) in saline subcutaneously once a week for 11 weeks at a dose rate of $7.4 \mathrm{mg} / \mathrm{kg}$ body weight. Animals intended for vehicle treatment were given an equal volume of normal saline subcutaneously.

At week 12, in six animals treated with azoxymethane and six controls treated with saline from each dietary group the colon was surgically removed and processed for both aberrant crypt foci (ACF) count and assay of mucosal fatty acid composition as described below. The remaining animals were colectomised 19 weeks after the first azoxymethane or saline dose, and mucosal fatty acid composition and the number, size, and location of all identifiable intestinal tumours evaluated. Only one of the animals (carcinogen treated; $\mathrm{n} 3$ diet) died before the scheduled termination of the experiment. Colectomy was performed through a midline laparotomy under total anaesthesia achieved with $100 \mathrm{mg}$ intraperitoneal thiopental. After colectomy, animals were not allowed to recover from the anaesthesia.

In vivo local release of $\mathrm{PGE}_{2}$ was assessed in intracolonic dialysates on the day before colectomy at week 12 .

ANALYSIS OF ACF

For ACF assessment, the colons were removed, opened longitudinally, and flushed with cool normal saline. Three $0.5 \mathrm{~cm}^{2}$ sections of the left colon, taken at $2 \mathrm{~cm}$ intervals, were fixed flat between filter papers in $10 \%$ buffered formalin for 24 hours. Each section was then stained with $0.2 \%$ methylene blue in saline for five minutes, rinsed in saline, and placed on microscope slides with the mucosal side up. ACFs were identified from normal crypts using a light microscope at a magnification of $40 \times$ by their 
increased pericryptal zone, elliptic or circular luminal opening, and greater thickness of the epithelial lining containing one or more crypts, which were seen to stain an intense blue. ${ }^{14}$ Crypt multiplicity was determined as the total number of aberrant crypts per rat.

MUCOSAL FATTY ACID ANALYSIS

After colonic sections for ACF analysis had been obtained, the remaining colonic mucosa was scraped off using a microscope slide, placed in cryovials, immediately flash frozen in liquid $\mathrm{N}_{2}$, and stored at $-80^{\circ} \mathrm{C}$ until fatty acid assay.

Fatty acid assay was performed as previously described. ${ }^{15}$ Tissue samples were put in a $4: 1$ $(\mathrm{v} / \mathrm{v})$ methanol/benzene solution and shaken for about one minute in a vortex mixer. Afterwards they were homogenised by sonication in an ultrasound bath. Direct transesterification of fatty acids was immediately carried out by the procedure of Lepage and Roy. ${ }^{16}$ The benzene extract was evaporated under a stream of nitrogen at $40^{\circ} \mathrm{C}$ to complete dryness. The residue was dissolved in $100 \mu \mathrm{l}$ benzene, and a $1 \mu \mathrm{l}$ aliquot was injected into the chromatograph. Fatty acid methyl esters were quantified by gas liquid chromatography in a PerkinElmer Autosystem chromatograph (PerkinElmer, Norwalk, Connecticut, USA) using a $30 \mathrm{~m}$ capillary column, $0.25 \mathrm{~mm}$ internal diameter, impregnated with SP 2330 as stationary phase. The fatty acid methyl esters were identified and quantified by comparison with an external standard (Sigma Chemical, St Louis, Missouri, USA). Fatty acids from $\mathrm{C}_{16: 0}$ to $\mathrm{C}_{24: 0}$ were measured, unidentified peaks accounting for $<0.5 \%$. They were expressed as molar percentage of total fatty acids present.

INTRACOLONIC DIALYSIS AND PGE ${ }_{2}$ ASSAY

$\mathrm{PGE}_{2}$ release into the lumen of the colon was assessed by in vivo intracolonic dialysis as previously described. ${ }^{17}$ Rats were anaesthetised by intraperitoneal administration of $1.5 \mathrm{ml} / \mathrm{kg}$ of a solution containing $23 \mathrm{mg} / \mathrm{ml}$ ketolar, $2 \mathrm{mg} / \mathrm{ml}$ diazepam, and $0.2 \mathrm{mg} / \mathrm{ml}$ atropine, and intracolonic dialysis was performed using hydrated Visking seamless cellulose tubing $(8 / 32 ; 6.3$ $\mathrm{mm}$ diameter; $7 \mathrm{~cm}$ long; Medicell International, London, UK) attached by a $10 \mathrm{~cm}$ polyurethane cannula to an external syringe. After the entire cannula had been inserted into the distal colon, the dialysis bag was filled with $1 \mathrm{ml}$ dialysis solution, consisting of $0.3 \%$ bovine serum albumin in a solution of 120 $\mathrm{mmol} / 1 \mathrm{NaCl}$ and $30 \mathrm{mmol} / 1 \mathrm{KHCO}_{3}$ adjusted to $\mathrm{pH}$ 7.9. One hour later, the fluid was withdrawn and immediately stored at $-80^{\circ} \mathrm{C}$. A one hour dialysis period was chosen as a compromise between the time needed for equilibration and the irritant effect of the dialysis bag on $\mathrm{PGE}_{2}$ production. ${ }^{18} 19$

The volume of the dialysate recovered at the end of the one hour period was larger than $90 \%$. During this period, there was no evidence of active diarrhoea, faecal staining of the dialysis bag, or changes in dialysis fluid volume, suggesting that the $\mathrm{PGE}_{2}$ measurements reflected production from the adjacent tissue and were not affected by fluid production in other parts of the colon. ${ }^{18}$

Tritiated standards of $\mathrm{PGE}_{2}$ were purchased from Amersham International (Amersham, Buckinghamshire, UK). Standards of $\mathrm{PGE}_{2}$ for high performance liquid chromatography (HPLC) analysis were obtained from Sigma. All solvents used in extraction and analysis were HPLC grade. Extraction of prostaglandins was performed using SepPak $\mathrm{C}_{18}$ Plus cartridges (Waters Associates, Milford, Massachusetts, USA) by a modification of the method of Powell. ${ }^{20}{ }^{21}$ In brief, after sample addition, the cartridges were successively washed with $10 \mathrm{ml}$ bidistilled water ( $\mathrm{pH}$ 3.15) and $10 \mathrm{ml}$ petroleum ether. Afterwards, prostaglandins were eluted with $5 \mathrm{ml}$ methyl formate. $\mathrm{C}_{18}$ cartridge recoveries were measured, after vacuum evaporation of eluates to dryness and redissolution in acetonitrile, by scintillation counting of the eluates. ${ }^{20}$ Recovery for $\mathrm{PGE}_{2}$ was 90.1 (2.7)\% (mean (SD), $\mathrm{n}=5$ ).

$\mathrm{PGE}_{2}$ determination was carried out using reverse phase HPLC. ${ }^{22}{ }^{23}$ The HPLC system consisted of a Perkin-Elmer HPLC Isocratic Lc 250 pump, and a variable wavelength (190-300 nm) Perkin-Elmer Lc 290 UV spectrophotometric detector. The reverse phase HPLC column used was a Kromasil $100 \mathrm{C}_{18}(5 \mu \mathrm{m} ; 150$ $\times 4.6 \mathrm{~mm}$; Teknokroma, Barcelona, Spain). The mobile phase was water/acetonitrile (67.2:32.8, v/v), adjusted to $\mathrm{pH} 2.6$ with $\mathrm{H}_{3} \mathrm{PO}_{4}$; the flow rate was isocratic to $1 \mathrm{ml} / \mathrm{min}$ and the detection wavelength $196 \mathrm{~nm}$. These conditions gave a fairly good separation and resolution of prostaglandins, as previously described. ${ }^{22}$ The eluates were collected in $1 \mathrm{ml}$ fractions (FRAC 100 collector; Pharmacia Biotech, Barcelona, Spain). Using this separation, $\mathrm{PGE}_{2}$ is eluted at 12.7 minutes and prostaglandin $\mathrm{E}_{3}$ at 8.3 minutes. A three minute fraction (from one minute before to one minute after the elution time) was collected for $\mathrm{PGE}_{2}$ determination. A PGE 2 EIA kit (Cayman Chemical, Ann Arbor, Michigan, USA) was used to quantify the $\mathrm{PGE}_{2}$ in the fraction.

HISTOLOGICAL ANALYSIS OF TUMOURS

Tumours larger than $1 \mathrm{~mm}$ in diameter which could be identified with the naked eye were excised, fixed in $10 \%$ formalin, embedded in paraffin wax, and processed individually. The specimens were cut into $5 \mu \mathrm{m}$ thick sections, and stained with haematoxylin and eosin for histological evaluation. All the slides were coded and examined by a pathologist who was unaware of the experimental group from which the specimens had been taken. The maximum size of each tumour was measured and the tumours were classified as adenomas or adenocarcinomas. The latter were graded by the degree of differentiation (well, moderate, or poor). Tumour incidence ( $\%$ animals with tumours) and tumour multiplicity (number of tumours/animal) were recorded.

STATISTICAL ANALYSIS

Results are expressed as mean (SEM) or as proportions. $\chi^{2}$ statistics were used to compare 


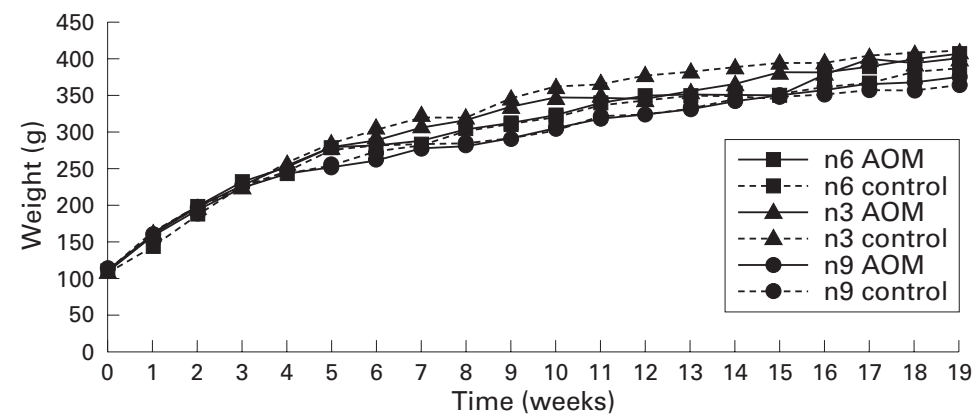

Figure 1 Mean body weights of animals over the course of the experiment.

qualitative variables. Significant differences between groups for quantitative parametric variables were evaluated using one way analysis of variance. Bonferroni test was used to assess where the differences occurred. Kruskall Wallis one way analysis of variance by rank and Mann Whitney U test were used for non-parametric variables. Statistical analysis was performed using SPSS for Windows 6.0 (SPSS Inc, Chicago, Illinois, USA).

\section{Results}

DIETARY INTAKE AND WEIGHT GAIN

There were no differences in the mean food intake either between azoxymethane and vehicle treated animals or among dietary groups.
Figure 1 shows the weight of the animals over the course of the experiment. Rats in every dietary group gained weight at comparable rates, no matter what the treatment was (azoxymethane or saline), except for vehicle treated rats on the $\mathrm{n} 3$ diet, which gained significantly more weight than the other vehicle treated groups ( $\mathrm{p}=0.01$ in weeks 12 and 14).

\section{FATTY ACID ANALYSIS}

Incorporation of dietary fatty acids into the colonic mucosa at week 12 was similar in saline and azoxymethane treated rats (tables 2, 3, and 4). As expected, rats fed the $\mathrm{n} 9$ diet had the highest mucosal concentrations of oleic acid, those fed the $\mathrm{n} 3$ diet had the highest concentrations of $\mathrm{n} 3$ long chain polyunsaturated fatty acids, and feeding the n6 diet resulted in the highest concentrations of linoleic acid in colonic mucosa.

At week 12, there were significant differences in the mucosal arachidonic acid to eicosapentaenoic acid (ARA:EPA) ratio among diets (saline and azoxymethane treated rats: $\mathrm{p}<0.0005 ; \mathrm{n} 6 v \mathrm{n} 9$ and $\mathrm{n} 3$; $\mathrm{n} 9 v \mathrm{n} 3$ ). On the other hand, there were no differences in the mucosal fatty acid profile between azoxymethane and saline treated rats, except for animals fed the n6 diet. In these rats, carcinogen administration was associated with a significant

Table 2 Mucosal fatty acid profile (\%) in rats fed the $n 9$ diet at weeks 12 and 19 after the first dose of carcinogen or vehicle

\begin{tabular}{|c|c|c|c|c|c|c|}
\hline \multirow[b]{2}{*}{$n 9$ diet } & \multicolumn{3}{|l|}{ Week 12} & \multicolumn{3}{|l|}{ Week 19} \\
\hline & Control & $A O M$ & p Value & Control & $A O M$ & $p$ Value \\
\hline SFAs & $34.6 \quad(0.45)$ & $33.6 \quad(0.24)$ & 0.11 & $31.1 \quad(1.7)$ & 33.6 (1.01) & 0.25 \\
\hline MUFAs & 46.9 (1.92) & $46.6 \quad(0.83)$ & 0.85 & $56.6 \quad(5.7)$ & $52.1(2.9)$ & 0.52 \\
\hline $\mathrm{C}_{18} \mathrm{n} 9$ & $35.1 \quad(1.62)$ & $36.03(0.78)$ & 0.62 & $45.7 \quad(5.7)$ & $41.4 \quad(3.1)$ & 0.39 \\
\hline n3 PUFAs & $1.22(0.20)$ & $1.28(0.14)$ & 0.63 & $0.59(0.15)^{\star}$ & $1.99(0.45)$ & 0.09 \\
\hline $\mathrm{C}_{18: 3} \mathrm{n} 3$ & $0.08(0.02)$ & $0.06(0.01)$ & 0.87 & $0.07(0.01)$ & $1.25(0.34) \dagger$ & 0.055 \\
\hline $\mathrm{C}_{20.5} \mathrm{n} 3$ & $0.15(0.02)$ & $0.16(0.02)$ & 0.94 & $0.09(0.03)$ & $0.11(0.03)$ & 0.62 \\
\hline $\mathrm{C}_{22: 6} \mathrm{n} 3$ & $0.80(0.09)$ & $0.98(0.11)$ & 0.25 & $0.41(0.10)^{\star}$ & $0.53(0.12) \dagger$ & 0.39 \\
\hline n6 PUFAs & $17.2(1.88)$ & $18.5(0.74)$ & 0.87 & 11.7 & $12.2(2.2) \dagger$ & 0.91 \\
\hline $\mathrm{C}_{18: 2} \mathrm{n} 6$ & $4.15(0.30)$ & $4.77(0.25)$ & 0.33 & $3.41(0.79)$ & $3.47(0.39)+\dagger$ & 0.94 \\
\hline $\mathrm{C}_{20: 3}^{18: 2} \mathrm{n} 6$ & $1.68(0.27)$ & $1.65(0.09)$ & 0.91 & $0.80(0.36)$ & $0.79(0.19)+\dagger$ & 0.97 \\
\hline $\mathrm{C}_{20.4} \mathrm{n} 6$ & $9.90(1.25)$ & $10.36(0.42)$ & 0.87 & $6.4(2.5)$ & $5.7(1.37)+\dagger$ & 0.66 \\
\hline ARA:EPA & $63.6(5.5)$ & $69.4 \quad(7.44)$ & 0.55 & $77.1 \quad(6.7)$ & $56.1(12.3)$ & 0.20 \\
\hline
\end{tabular}

Values are expressed as mean (SEM)

${ }^{\star} \mathrm{p}<0.05 v$ controls at week 12 .

$t p<0.05$ and $t+p<0.01 v$ AOM at week 12 .

AOM, azoxymethane; SFA, saturated fatty acid; MUFA, monounsaturated fatty acid; PUFA, polyunsaturated fatty acid; ARA:EPA, arachidonic acid to eicosapentanoic acid ratio.

Table 3 Mucosal fatty acid profile (\%) in rats fed the $n 3$ diet at weeks 12 and 19 after the first dose of carcinogen or vehicle

\begin{tabular}{|c|c|c|c|c|c|c|}
\hline \multirow[b]{2}{*}{$n 3$ diet } & \multicolumn{3}{|l|}{ Week 12} & \multicolumn{3}{|l|}{ Week 19} \\
\hline & Controls & $A O M$ & $p$ Value & Controls & $A O M$ & $p$ Value \\
\hline SFAs & $38.3 \quad(1.27)$ & $36.9 \quad(1.21)$ & 0.48 & $31.9(1.93)^{\star}$ & $32.7 \quad(3.2)$ & 0.25 \\
\hline MUFAs & 35.9 (3.10) & $37.8 \quad(1.43)$ & 0.60 & $31.8 \quad(1.04)$ & $32.2(1.84) \dagger$ & 0.86 \\
\hline $\mathrm{C}_{18: 1} \mathrm{n} 9$ & $23.9 \quad(2.20)$ & $25.5 \quad(1.19)$ & 0.57 & 19.5 (3.03) & 16.8 (3.9)† & 0.58 \\
\hline n3 PUFAs & $10.8 \quad(2.20)$ & $9.8 \quad(1.07)$ & 0.67 & $15.4 \quad(1.07)$ & $13.6(1.6)$ & 0.36 \\
\hline $\mathrm{C}_{18: 3} \mathrm{n} 3$ & $0.12(0.02)$ & $0.13(0.01)$ & 0.95 & $0.88(0.73)$ & $1.64(0.92)$ & 0.53 \\
\hline $\mathrm{C}_{20.5} \mathrm{n} 3$ & $5.76(1.27)$ & $5.46(0.74)$ & 0.84 & $8.3 \quad(0.95)$ & $5.4 \quad(0.61)$ & 0.024 \\
\hline $\mathrm{C}_{22: 6} \mathrm{n} 3$ & $3.48(0.76)$ & $2.88(0.30)$ & 0.48 & $4.17(0.26)$ & $3.9(0.26) \dagger$ & 0.50 \\
\hline n6 PUFAs & $14.9 \quad(1.81)$ & $15.4 \quad(1.51)$ & 0.83 & $20.8 \quad(2.27)$ & 21.5 & 0.87 \\
\hline $\mathrm{C}_{18: 2} \mathrm{n} 6$ & $7.08(0.46)$ & $7.22(0.31)$ & 0.82 & $7.65(0.69)$ & $7.01(0.81)$ & 0.57 \\
\hline $\mathrm{C}_{20: 3} \mathrm{n} 6$ & $1.22(0.23)$ & $1.48(0.24)$ & 0.46 & $1.83(0.55)$ & $2.32(0.70)$ & 0.59 \\
\hline $\mathrm{C}_{20: 4} \mathrm{n} 6$ & $5.33(1.00)$ & $5.39(0.85)$ & 0.96 & $6.92(0.56)$ & $5.2(0.59)$ & 0.053 \\
\hline ARA:EPA & $1.00(0.10)$ & $0.97(0.06)$ & 0.78 & $0.86(0.07)$ & $0.96(0.06)$ & 0.63 \\
\hline
\end{tabular}

Values are expressed as mean (SEM).

${ }^{\star} \mathrm{p}<0.05 v$ controls at week 12 .

$\mathrm{tp}<0.05 v \mathrm{AOM}$ at week 12 .

AOM, azoxymethane; SFA, saturated fatty acid; MUFA, monounsaturated fatty acid; PUFA, polyunsaturated fatty acid; ARA:EPA, arachidonic acid to eicosapentanoic acid ratio. 
Table 4 Mucosal fatty acid profile (\%) in rats fed the $n 6$ diet at weeks 12 and 19 after the first dose of carcinogen or vehicle

\begin{tabular}{|c|c|c|c|c|c|c|c|c|}
\hline \multirow[b]{2}{*}{$n 6$ diet } & \multicolumn{3}{|l|}{ Week 12} & \multicolumn{5}{|c|}{ Week 19} \\
\hline & Controls & $A O M$ & $p$ Value & Controls & & $A O M$ & & $p$ Value \\
\hline SFAs & $(0.30)$ & $35.8(0.49)$ & 0.022 & 33.7 & $(0.50)$ & 35.5 & $(0.44)$ & 0.025 \\
\hline MUFAs & $23.9 \quad(0.22)$ & $22.8 \quad(0.62)$ & 0.12 & 25.8 & $(1.07)$ & 24.3 & $(0.74)$ & 0.52 \\
\hline $\mathrm{C}_{18.1} \mathrm{n} 9$ & $16.9(0.21)$ & $15.8 \quad(0.46)$ & 0.06 & 19.8 & $(0.87)^{\star}$ & 18.4 & $(0.77) \dagger$ & 0.42 \\
\hline n3 PUFAs & $0.63(0.03)$ & $0.62(0.04)$ & 0.93 & 0.81 & $(0.07)^{\star}$ & 0.65 & $(0.03)$ & 0.08 \\
\hline $\mathrm{C}_{18 \cdot 3} \mathrm{n} 3$ & $0.08(0.01)$ & $0.08(0.01)$ & 0.82 & 0.10 & $(0.01)$ & 0.07 & $(0.01)$ & 0.08 \\
\hline $\mathrm{C}_{20: 5} \mathrm{n} 3$ & $0.11(0.003)$ & $0.12(0.02)$ & 0.37 & 0.11 & $(0.01)$ & 0.11 & $(0.01)$ & 0.81 \\
\hline $\mathrm{C}_{22.6} \mathrm{n} 3$ & $0.39(0.02)$ & $0.37(0.02)$ & 0.49 & 0.46 & $(0.06)$ & 0.38 & $3(0.02)$ & 0.11 \\
\hline n6 PUFAs & $41.1 \quad(0.44)$ & $40.6 \quad(0.91)$ & 0.61 & 39.6 & $(0.63)$ & 39.5 & $(0.45)$ & 0.87 \\
\hline $\mathrm{C}_{18: 2} \mathrm{n} 6$ & $16.1 \quad(0.48)$ & $16.7(1.20)$ & 0.64 & 19.5 & $(1.06)^{\star}$ & 18.02 & $(1.25)$ & 0.20 \\
\hline $\mathrm{C}_{20.3} \mathrm{n} 6$ & $2.42(0.15)$ & $2.84(0.15)$ & 0.08 & 1.70 & $(0.20)^{\star}$ & 1.88 & $3(0.12)+t$ & 0.42 \\
\hline $\mathrm{C}_{20: 4} \mathrm{n} 6$ & $19.9(0.56)$ & $18.4 \quad(0.26)$ & 0.051 & 15.8 & $(1.00)^{\star \star}$ & 16.9 & $(1.19)$ & 0.26 \\
\hline ARA:EPA & 189.2 & $161.6 \quad(23.2)$ & 0.26 & 146.4 & $(11.4) \star$ & 152.2 & $(9.1)$ & 0.99 \\
\hline
\end{tabular}

Values are expressed as mean (SEM).

${ }^{\star} \mathrm{p}<0.05$ and ${ }^{\star \star} \mathrm{p}<0.01 v$ controls at week 12 .

$\mathrm{tp}<0.05$ and $\dagger+\mathrm{p}<0.01 v \mathrm{AOM}$ at week 12 .

AOM, azoxymethane; SFA, saturated fatty acid; MUFA, monounsaturated fatty acid; PUFA, polyunsaturated fatty acid; ARA:EPA, arachidonic acid to eicosapentanoic acid ratio.

increase in the molar percentage of saturated fatty acids.

At week 19, the differences in the ARA:EPA ratio between the diets were similar to those at week 12 (saline and azoxymethane treated rats: $\mathrm{p}<0.0005 ; \mathrm{n} 6 v \mathrm{n} 9$ and $\mathrm{n} 3$, and $\mathrm{n} 9 v \mathrm{n} 3$ ). On the other hand, there were only slight differences in the mucosal fatty acid profile between azoxymethane and saline treated rats, with a significant decrease in the concentrations of $\mathrm{EPA}$ in the $\mathrm{n} 3$ diet group, and an increase in saturated fatty acid concentrations in animals fed the n 6 diet.

Animals fed the $\mathrm{n} 9$ diet showed a decrease in all n6 polyunsaturated fatty acids at week 19 as compared with week 12, particularly azoxymethane treated rats. Mucosal arachidonate concentrations decreased significantly in this dietary group, reaching values similar to those of animals fed the n3 diet, and significantly lower than those in the n6 diet group (azoxymethane treated rats: $\mathrm{p}=0.003 ; \mathrm{n} 6 v \mathrm{n} 3$ and $\mathrm{n} 9$ ). In addition, rats fed the $\mathrm{n} 9$ diet showed a significant decrease in docosahexaenoic acid $\left(\mathrm{C}_{22: 6} \mathrm{n} 3\right)$ and a significant increase in $\alpha$-linolenic acid $\left(\mathrm{C}_{18: 3} \mathrm{n} 3\right)$ at week 19 . On the other hand, rats in the $\mathrm{n} 3$ diet group showed a significant decrease in oleic acid and an increase in docosahexaenoic acid concentrations at week 19 as compared with week 12 , especially azoxymethane treated rats. In addition, azoxymethane treated rats in the $n 6$ diet group showed a slight but significant increase in oleic acid concentrations and a decrease in dihomogammalinoleic acid $\left(\mathrm{C}_{20: 3} \mathrm{n} 6\right)$ concentrations at week 19 .

ASSAY OF $\mathrm{PGE}_{2}$

Figure 2 gives intracolonic $\mathrm{PGE}_{2}$ concentrations at week 12. Azoxymethane treated rats fed $n 6$ fat released significantly higher amounts of $\mathrm{PGE}_{2}$ into the colonic lumen than both the other azoxymethane treated groups and the vehicle treated rats. In contrast, rats on the $\mathrm{n} 3$ diet treated with the carcinogen showed a slight but significant decrease in the release of $\mathrm{PGE}_{2}$, and rats in the $\mathrm{n} 9$ diet group did not show any change compared with vehicle treated rats. On the other hand, $\mathrm{PGE}_{2}$ release in vehicle treated

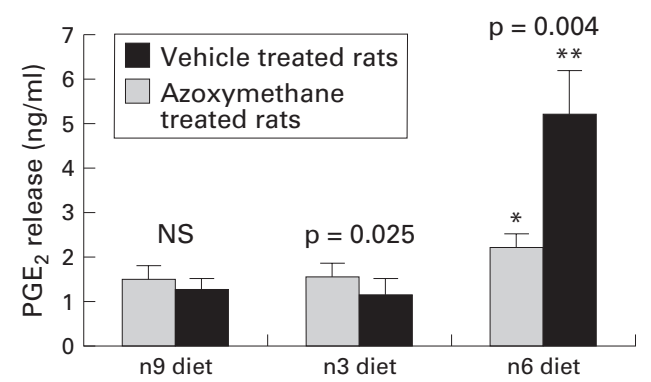

Figure 2 Effect of dietary fat on intracolonic prostaglandin $E_{2}\left(P G E_{2}\right)$ release 12 weeks after the first dose of carcinogen or vehicle. Results are mean (SEM); $n=$ 4 to 6 per group. ${ }^{*} p=0.02$ compared with results for the $n 9$ diet; $* \star p=0.002$ compared with results for the $n 3$ and $n 9$ diets.

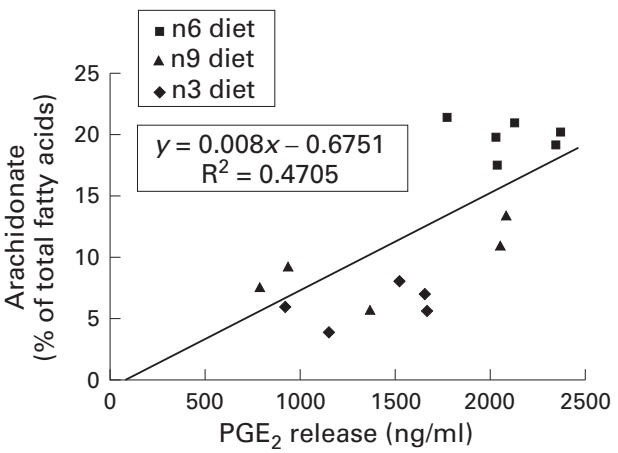

Figure 3 Significant correlation between mucosal arachidonate concentrations and dialysate prostaglandin $E$ $\left(P G E_{2}\right)$ release in vehicle treated rats.

$\mathrm{n} 9$ diet fed rats was significantly lower than in the $\mathrm{n} 6$ diet group.

A significant correlation between mucosal arachidonate concentrations and intracolonic $\mathrm{PGE}_{2}$ release was observed in both vehicle treated $(r=0.686 ; \mathrm{p}=0.002)$ and carcinogen treated rats $(r=0.889 ; \mathrm{p}<0.0005)$ (figs 3 and 4 ). Whereas in vehicle treated rats this correlation was linear, in azoxymethane treated animals it was logarithmic because of the pronounced increase in $\mathrm{PGE}_{2}$ concentrations in the rats fed the $\mathrm{n} 6$ diet.

ACF FORMATION

Figure 5 shows the number of ACF and crypt multiplicity. Animals administered saline showed no evidence of ACF formation in the 


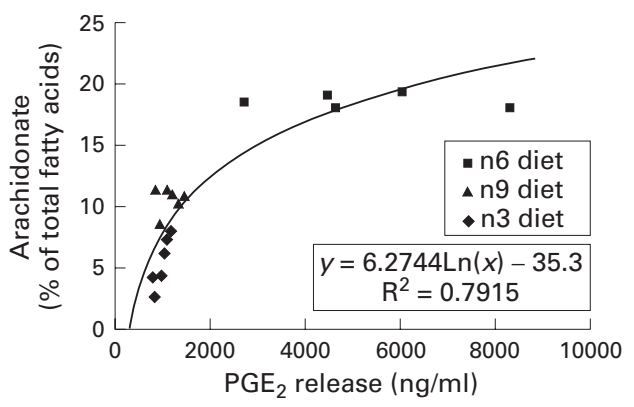

Figure 4 Significant correlation between mucosal arachidonate concentrations and dialysate prostaglandin $E_{2}$ $\left(P G E_{2}\right)$ release in carcinogen treated rats.

colon, whereas all azoxymethane treated rats developed ACF. In animals fed the $\mathrm{n} 9$ and $\mathrm{n} 3$ diets, azoxymethane induced significantly less ACF per rat than those fed the $n 6$ diet (overall $\mathrm{p}=0.0062 ; \mathrm{n} 9$ and $\mathrm{n} 3$ diets $v \mathrm{n} 6$ diet). This was mainly due to a decrease in foci with one or two aberrant crypts in the $\mathrm{n} 9$ diet group, and in foci with four crypts in the $\mathrm{n} 3$ diet group. However, the total number of aberrant crypts per rat (crypt multiplicity) was also significantly lower in both the $\mathrm{n} 9$ and $\mathrm{n} 3$ diet groups than in the $\mathrm{n} 6$ diet group (overall $\mathrm{p}=0.0044$ ).

\section{TUMOUR FORMATION}

Animals treated with saline showed no evidence of tumour formation at either 12 or 19 weeks. Likewise, azoxymethane treated rats showed no evidence of tumours at week 12 . However, 19 weeks after the first injection of azoxymethane, colonic adenocarcinomas developed in seven of $12(58 \%)$ rats of the $\mathrm{n} 9$ diet group, in five of $11(45 \%)$ rats fed the $\mathrm{n} 3$ diet,
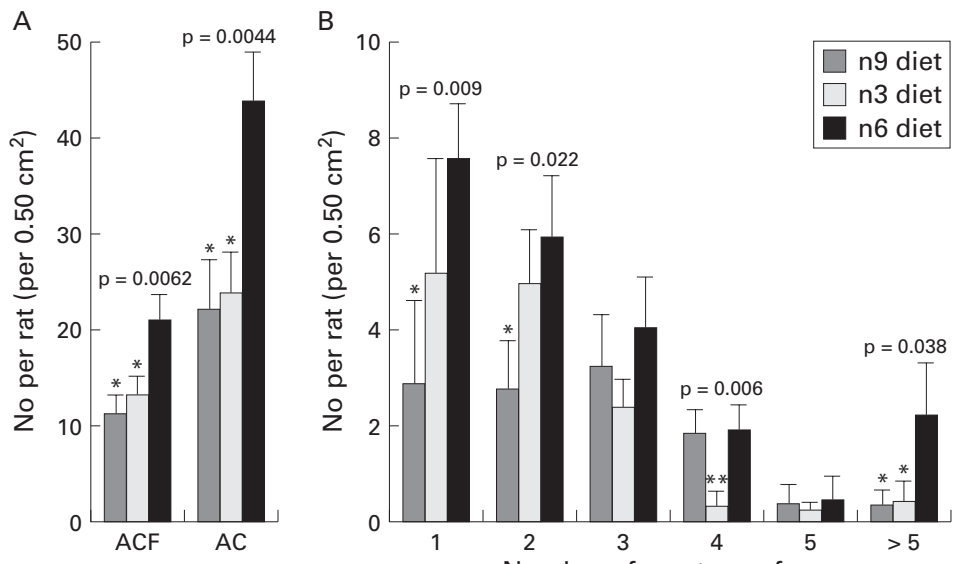

Figure 5 (A) Comparison of total number of aberrant crypt foci (ACF) and total number of aberrant crypts (AC) per rat by dietary group ( $n=6$ per group); (B) comparison of the total number of $A C F$ by number of crypts per focus and by dietary group $(n=6 \mathrm{per}$ group). Results are mean (SEM) per $0.50 \mathrm{~cm}^{2} .{ }^{\star} p<0.05$ v n6 diet; ${ }^{\star \star} p<0.05$ v n6 and $n 9$ diets.

Table 5 Histology of colon tumours in azoxymethane treated rats 19 weeks after the first dose of carcinogen

\begin{tabular}{llll}
\hline $\begin{array}{l}\text { Histological parameter } \\
\text { (adenocarcinomas=10) }\end{array}$ & $\begin{array}{l}n 3 \text { diet } \\
\text { (adenocarcinomas=8) }\end{array}$ & $\begin{array}{l}n 6 \text { diet } \\
\text { (adenocarcinomas=30) }\end{array}$ \\
\hline $\begin{array}{l}\text { Well differentiated } \\
\begin{array}{l}\text { Moderately } \\
\text { differentiated }\end{array}\end{array}$ & $3(30)$ & $2(25)$ & $6(20)$ \\
$\begin{array}{l}\text { Poorly differentiated } \\
\text { (a) }\end{array}$ & 0 & $4(50)$ & $6(20)$ \\
\hline
\end{tabular}

Numbers in parentheses are percentage of tumour per total colon tumours with each diet. ${ }^{\star \star} \mathrm{p}=0.01 \mathrm{n} 6 v \mathrm{n} 9$ diet. and in 10 of $12(83 \%)$ rats of the n6 diet group $(\mathrm{p}=0.15)$. Neither benign adenomas nor metastatic invasion of the colonic tumours to the liver, peritoneum, or regional lymph nodes were observed. The number of malignant colonic tumours per rat was $0.8(0.2), 0.7$ (0.3), and $2.5(0.8)$ for the $n 9, n 3$, and $n 6$ diet groups respectively $(\mathrm{p}=0.03 ; \mathrm{n} 9$ and $\mathrm{n} 3 v \mathrm{n} 6$ diet). Tumour localisation was different in the different dietary groups. Thus animals on the $\mathrm{n} 3$ and $\mathrm{n} 6$ diets had a predominance of colon tumours in the distal half of the colon (seven of eight tumours and 28 of 30 tumours respectively) as compared with those on the $\mathrm{n} 9$ diet (five of 10 tumours) ( $\mathrm{p}=0.006 ; \mathrm{n} 9 v \mathrm{n} 6$ groups). Mean tumour size was not significantly different among the groups. However, animals fed the $\mathrm{n} 9$ and $\mathrm{n} 3$ diets showed a lower percentage of poorly differentiated adenocarcinomas than those fed the n6 diet (table 5).

\section{Discussion}

The preventive or inhibitory effect of $\mathrm{n} 3$ fatty acids (fish oil) on experimental colon carcinogenesis has been widely evaluated. ${ }^{35924}$ Fish oil has also been reported to suppress rectal cell proliferation in both healthy human subjects ${ }^{25}$ and patients with colonic adenomas. ${ }^{26}$ In contrast, the effect of $\mathrm{n} 9$ fatty acids on colon carcinogenesis has been scarcely assessed. Thus, the results of this study showing that an experimental diet containing 5\% olive oil has an anticarcinogenic effect similar to that of n3 fatty acids may be of relevance.

The use of precancer events to predict the effects of diets on colon carcinogenesis is of great interest because it would simplify the experimental design of animal studies. We chose to investigate alterations in the occurrence of $\mathrm{ACF}$ as surrogate biomarker of carcinogenic changes in the rat colon during the initiation phase of colon carcinogenesis. ${ }^{27-30}$ ACF have been recently reported to represent preneoplastic lesions of colon cancer in both rodents $^{31}$ and humans. ${ }^{33}$ However, known inhibitors of experimental colon carcinogenesis do not always prevent ACF formation. ${ }^{34}$ This may be related to differences in both the experimental model and the carcinogenic regimen used. Thus, contrasting the effect of interventions on the premalignant biomarkers with their late effects on colon cancer development, as shown in this study, seems to be a prudent approach. In the present work, $\mathrm{n} 9$ and $\mathrm{n} 3$ diets significantly inhibited ACF formation, and both types of diet similarly inhibited the subsequent development of colonic tumours when compared with $\mathrm{n} 6$ fatty acids. In fact, the effects of these diets on the number of ACF paralleled the effects on tumours. Thus, using the present experimental design, the effect of dietary fatty acids on ACF numbers seems likely to be a useful predictor of tumour occurrence.

It has been suggested that ACF formation and ACF growth should be examined independently, as an intervention could presumably suppress the initial formation of single aberrant crypts and/or prevent single ACF from increasing in size. ${ }^{34}$ In this study, the $\mathrm{n} 9$ and $\mathrm{n} 3$ diets 
decreased the number of ACF similarly. However, feeding the $\mathrm{n} 9$ diet was mainly associated with a reduction in ACF with one or two crypts, whereas $\mathrm{n} 3$ diet consumption predominantly decreased ACF with four crypts. In spite of this, there were no differences in the later development of colon carcinoma between these two groups. In agreement with these findings, the size of a focus (number of aberrant crypts in a focus) was not predictive of subsequent development of tumours in a recent study. ${ }^{35}$ The differences in ACF size in rats on the $\mathrm{n} 3$ and $\mathrm{n} 9$ diets suggest that these fatty acids act in different phases of ACF formation and growth, and thus the possibility that they may act synergistically should be explored.

Besides the incidence and multiplicity of tumours, we observed differences in the degree of differentiation of carcinomas between diets. Previous studies have produced contradictory results in relation to the effect of the $\mathrm{n} 3$ diet on tumour differentiation. Recently, it was shown that dietary $\mathrm{n} 3$ fats reduce tumour yields and improve the degree of differentiation of carcinomas at colorectal anastomosis in rats. ${ }^{36}$ These findings contrast with a previous paper showing that, although dietary EPA reduced tumour yield, the tumours were not as well differentiated as those from animals fed $n 6$ fat. ${ }^{9}$ The present findings, showing a trend to a higher degree of differentiation with $\mathrm{n} 3$ diets as compared with $\mathrm{n} 6$ fat, are in agreement with the first study. However, the significant effect of $\mathrm{n} 9$ fat on the degree of differentiation has not been previously described. These results suggest an effect of $n 3$ and $n 9$ fatty acids on cell differentiation; the intrinsic mechanisms of such effects should be further investigated.

The antitumour effect of a fish oil diet has been attributed to its content of EPA rather than docosahexaenoic acid. ${ }^{37}$ In humans, fish oil supplementation, which is associated with a doubling of the rectal mucosal EPA content, significantly decreased the rectal mucosa cell proliferative indices. ${ }^{26}$ In addition, a stepwise reduction in tissue EPA values in the human colonic adenoma dysplasia carcinoma sequence has been described. ${ }^{15}$ On the other hand, it has been suggested that the dietary $n 3$ to $\mathrm{n} 6$ ratio is involved in determining the effects of fish oil on rectal cell proliferation in humans. ${ }^{38}$ In that study, fish oil supplementation in subjects eating a high fat $\mathrm{n} 6$ diet had no antiproliferative effect, suggesting that in these subjects $\mathrm{n} 3$ fat supplementation was not able to decrease the mucosal ARA:EPA ratio, in spite of increasing EPA concentrations. ${ }^{38}$ Therefore, it seems that the goal of dietary interventions in colonic carcinogenesis should be to decrease the mucosal ARA:EPA ratio instead of merely increasing mucosal EPA concentrations. On the other hand, the antitumour effect of olive oil has been ascribed, in part, to its oleic acid content, the predominant fatty acid in olive oil (about $75 \%$ ). The present study shows that the n9 diet significantly decreased both mucosal arachidonate concentrations and ARA:EPA ratio as compared with the n 6 diet, which may in part account for the observed beneficial effect of olive oil. In addition to oleic acid, other components of olive oil, such as squalene, and flavonoid and polyphenolic compounds may have chemopreventive activity against colon carcinogenesis. With respect to this, results of a recent study showed that $1 \%$ squalene suppressed colonic ACF formation and crypt multiplicity in a model of experimental colonic carcinogenesis. ${ }^{39}$ Thus the antitumour effect observed with the $\mathrm{n} 9$ diet in the present study may also be due to its squalene content $(0.8 \%$ of the olive oil used in the $n 9$ diet).

Oleic acid is also found in the fat of beef and poultry (30-45\% of the fat) and in other vegetable oils, such as corn oil $(30 \%)$, soybean oil $(25 \%)$, and sunflower seed oil $(33 \%) .^{40}$ As these other fats and oils containing oleic acid generally act as promoters of chemically induced tumours in animals, it has been suggested that the oleic acid content of olive oil cannot account for its protective effect in cancer development. ${ }^{40}$ However, these other fats and oils are rich in either saturated fat or linoleic acid, and their administration is associated with an increase in the mucosal arachidonate content, and thus with an increase in the ARA:EPA ratio.

Methods for studying the role of eicosanoids in colon carcinogenesis include various in vitro assays, such as determination of the mucosal $\mathrm{PGE}_{2}$ concentration in tissue homogenates, ${ }^{9}$ generation and release of $\mathrm{PGE}_{2}$ by colonic biopsy specimens into the cell culture medium, ${ }^{25}$ and formation of prostaglandins from $\left[{ }^{14} \mathrm{C}\right]$ arachidonate through mucosal cyclooxygenase activity. ${ }^{41}$ However, measurements of tissue concentrations may be misleading because eicosanoids are not stored, but produced in response to tissue trauma-for example, mucosal trauma resulting from biopsy sampling may itself activate membrane bound phospholipases. ${ }^{42}$ Similar caveats apply to tissue culture techniques. ${ }^{44}$ Over the last few years, in vivo intracolonic dialysis against rectal mucosa, as performed in our study, has been suggested to be a more reliable index of the balance between eicosanoid production and degradation than in vitro incubations of colon mucosa. In fact, it has been widely used to assess in vivo eicosanoid release in experimental and human colitis. ${ }^{17-19} 4546$ Rectal dialysate collections probably arise from production by the adjacent colon without any contribution from secretions from other parts of the intestine. ${ }^{1646}$ On the other hand, although with a dialysis time of only one hour our measurements may have underestimated $\mathrm{PGE}_{2}$ concentrations, they avoided the artificial formation of $\mathrm{PGE}_{2}$ induced by the irritant effect of the dialysis bag. Nevertheless, dialysate $\mathrm{PGE}_{2}$ concentrations were considerably enhanced in the carcinogen treated animals fed the $\mathrm{n} 6$ fat diet as compared with the $\mathrm{n} 3$ and $\mathrm{n} 9$ groups, and correlated closely with mucosal arachidonate concentrations, suggesting that they are a good estimation of the mucosal production of this prostaglandin and are not derived from bacterial microflora.

As mentioned above, one possible mechanism by which $\mathrm{n} 3$ and $\mathrm{n} 9$ fats may exert their 
antitumour effect may be by influencing arachidonic acid metabolism. This fatty acid is in turn the precursor of the dienoic prostaglandins, and it has been shown that $\mathrm{PGE}_{2}$ stimulates in vitro colon cancer cell proliferation ${ }^{47}$ and inhibits apoptosis, ${ }^{48}$ suggesting a potential role for the arachidonate derived eicosanoids in human colon carcinogenesis. In this respect, previous studies have shown increased concentrations of $\mathrm{PGE}_{2}$ in colon cancer tissues in both humans and rats. ${ }^{4149}{ }^{50}$ It has been suggested that $\mathrm{n} 3$ fats may exert their anticarcinogenic effects by decreasing membrane arachidonic acid concentrations by competitive substitution, ${ }^{37}$ thereby reducing the synthesis of $\mathrm{PGE}_{2} \cdot{ }^{9}{ }^{25}{ }^{41}$ Results of the present study are in agreement with this hypothesis, as $\mathrm{n} 3$ fat suppressed the excessive production of $\mathrm{PGE}_{2}$ that accompanied $\mathrm{ACF}$ formation in the $\mathrm{n} 6$ fat diet group. On the other hand, competitive substitution of membrane arachidonate by $\mathrm{n} 9$ fats was also associated with unchanging intracolonic $\mathrm{PGE}_{2}$ release, suggesting that the antipromotional effect of $\mathrm{n} 9$ fats may also be mediated through inhibition of the formation of the dienoic prostaglandins. In addition to curtailing the formation of arachidonate metabolites, it has been suggested that the antipromotional action of $\mathrm{n} 3$ fats may be mediated by other mechanisms such as effects on oncogene expression, ${ }^{51-53}$ apoptosis, ${ }^{54-56}$ and intracellular signal transduction pathways. ${ }^{41}{ }^{57-59}$ Whether these mechanisms are also involved in the effects of $\mathrm{n} 9$ fats has to be further evaluated.

In conclusion, this study provides evidence that a $5 \%$ fat diet containing olive oil as compared with a $5 \%$ safflower oil diet prevents colonic carcinogenesis in rats, as occurs with $5 \%$ fish oil diets. This effect may be partly due to the modulation of arachidonate metabolism and local $\mathrm{PGE}_{2}$ synthesis. Whether there is a direct inhibitory effect of olive oil and fish oil on colon carcinogenesis, or whether there is only a deleterious effect of safflower oil needs further investigation.

The authors thank Drs Oriol Bulbena, Joan Roselló Catafau, and Emilio Gelpí of the Instituto de Investigaciones Biomédicas (Consejo Superior de Investigaciones Científicas, Barcelona) for (Consejo Superior de Investigaciones Científicas, Barcelona) for
helpful discussion on the preparation of the $\mathrm{PGE}_{2}$ assay, and $\mathrm{Dr}$ helpful discussion on the preparation of the $\mathrm{PGE}_{2}$ assay, and $\mathrm{Dr}$
Montserrat Fitó and Mrs Gloria Gómez for helpful technical Montserrat Fitó and Mrs Gloria Gómez for helpful technical
assistance. Scientific Hospital Supplies (Liverpool, UK) kindly assistance. Scientific Hospital Supplies (Liverpool, UK) kindly
provided the diets for the study. The study was supported by a provided the diets for the study. The study was supported by a
grant from the Fondo de Investigaciones Sanitarias (94/0611), grant from the Fondo de Investigaciones Sanitarias (94/0611),
National Institute of Health, Spain. R B was the recipient of a National Institute of Health, Spain. R B was the recipient of a
Grant for Research Training (FP 93/39867217) from the MinGrant for Research Training (FP 93/39867217) from the Min-
isterio de Educación y Ciencia, Spain. This work was presented isterio de Educación y Ciencia, Spain. This work was presented in part at the 97th and 98th Annual Meetings of the American Gastroenterological Association held in May 1997 and 1998, and Gastroenterology 1998;114:A563.

1 Burnstein MJ. Dietary factors related to colorectal neoplasms. Surg Clin N Am 1993;73:13-29.

2 Willett WC, Stampfer MJ, Colditz GA, et al. Relation of meat, fat, and fiber intake to the risk of colon cancer in a prospective study among women. $N$ Engl f Med 1990;323 1664-72.

3 Reddy BS. Dietary fat, calories, and fiber in colon cancer. Prev Med 1993;22:738-49.

4 Reddy BS, Maruyama H. Effect of different levels of dietary corn oil and lard during the initiation phase of colon carcinogenesis in F344 rats. 7 Natl Cancer Inst 1986;77: 815-22.

5 Reddy BS, Burill C, Rigotty J. Effect of diets high in $\omega-3$ and $\omega-6$ fatty acids on initiation and postinitiation stages of $\omega-6$ fatty acids on initiation and postinitiation
colon carcinogenesis. Cancer Res 1991;51:487-91.

6 Reddy BS, Maeura T. Tumour promotion by dietary fat in azoxymethane-induced colon carcinogenesis in female F344 rats: influence of amount and sources of dietary fat. $\mathcal{F}$ Natl Cancer Inst 1984;72:745-50.
7 Reeves PG, Nielsen FH, Fahey GC Jr. AIN-93 purified diets for laboratory rodents: final report of the American nstitute of Nutrition ad hoc writing committee on the reformulation of the AIN-76 ${ }^{\text {a }}$ rodent diet. $\mathcal{F}$ Nutr 1993;123 1939-51

8 Sakaguchi M, Hiramatsu Y, Takada H, et al. Effect of dietary unsaturated and saturated fats on azoxymethane-induced colon carcinogenesis in rats. Cancer Res 1984;44:1472-7.

9 Minoura T, Takata T, Sakaguchi M, et al. Effect of dietary eicosapentaenoic acid on azoxymethane-induced colon carcinogenesis in rats. Cancer Res 1988;48:4790-4.

10 Ferro-Luzzi A, Branca F. Mediterranean diet, Italian-style: prototype of a healthy diet. Am f Clin Nutr 1995;61(suppl): 338-45S.

11 Willett WC, Sacks F, Trichopoulos A, et al. Mediterranean diet pyramid: a cultural model for healthy eating. Am $\mathrm{f}$ Clin Nutr 1995;61 (suppl): 1402-6S

12 Boutron MC, Senesse P, Faivre J. Nutrients and the risk of left colon or rectal cancer [abstract]. Gastroenterology 1997; 112:A540.

13 Bautista D, Obrador A, Moreno V, et al. Ki-ras mutation modifies the protective effect of dietary monounsaturated fat and calcium on sporadic colorectal cancer. Cancer Epidemiol Biomarkers Prev 1997;6:57-61.

14 Bird Ranjana P. Observation and quantification of aberrant crypts in the murine colon treated with a colon carcinogen: crypts in the murine colon treated with a colon ca
preliminary findings. Cancer Lett 1987;37:147-51.

preliminary findings. Cancer Lett 1987;37:147-51.
15 Fernández-Bañares F, Esteve M, Navarro E, et al. Changes of the mucosal $n 3$ and $n 6$ fatty acid status occur early in the colorectal adenoma-carcinoma sequence. Gut 1996;38: 254-9.

16 Lepage G, Roy CC. Direct transesterification of all classes of lipids in one-step reaction. $\mathcal{F}$ Lipid Res 1986;27:114-20.

17 Bertran X, Mañé J, Fernández-Bañares F, et al. Intracolonic administration of zileuton, a selective 5-lipoxygenase inhibitor, accelerates healing in a rat model of chronic colitis. Gut 1996;38:899-904.

18 Zipser RD, Nast CC, Lee $M$, et al. In vivo production of leukotriene $\mathrm{B}_{4}$ and leukotriene $\mathrm{C}_{4}$ in rabbit colitis. Relationship to inflammation. Gastroenterology 1987;92:33-9.

19 Lauritsen K, Laursen LS, Bukhave K, et al. In vivo profiles of eicosanoids in ulcerative colitis, Crohn's colitis, and Clostridium difficile colitis. Gastroenterology 1988;95:1117

20 Ramis I, Roselló-Catafau J, Artigot M, et al. Simultaneous reversed-phase extraction of lipoxygenase and ciclooxygenase metabolites of arachidonic acid in nasal secretions: methodological aspects. F Chromatogr 1990; 532:217-25.

21 Powell WS. Rapid extraction of arachidonic acid metabolites from biological samples using octadecylsilyl silica. Methods Enzymol 1982;86:467-77.

22 Brouard C, Pascaud M. Effects of moderate dietary supplementations with $\mathrm{n} 3$ fatty acids on macrophage and lymphocyte phospholipids and macrophage eicosanoid
synthesis in the rat. Biochim Biophys Acta 1990;1047:19-28.

23 Terragno A, Rydzik R, Terragno NA. High performance liquid chromatography and UV detection for the separation and quantitation of prostaglandins. Prostaglandins 1981;21: 101-12.

24 Reddy BS, Sugie S. Effect of different levels of omega-3 and omega-6 fatty acids on azoxymethane-induced colon carcinogenesis in F344 rats. Cancer Res 1988;48:6642-7.

25 Bartram HP, Gostner A, Scheppach W, et al. Effect of fish oil on rectal cell proliferation, mucosal fatty acids, and prostaglandin E2 release in healthy subjects. Gastroenterology 1993;105:1317-22.

26 Anti M, Armelao F, Marra G, et al. Effects of different doses of fish oil on rectal cell proliferation in patients with sporadic colonic adenomas. Gastroenterology 1994;107: 1709-18.

27 Fearon ER, Vogelstein B. A genetic model for colorectal tumorigenesis. Cell 1990;61:759-67.

28 Wargovich MJ, Medline A, Bruce WR. Early histopathologic events in the evolution of colon cancer in C57BL/6 and CF1 mice treated with 1,2-dimethylhydrazine. 7 Natl Cancer Inst 1983;71:125-31.

29 Pretlow TP. Aberrant crypt foci and k-ras mutations: earliest recognized players or innocent bystanders in colon carcinogenesis. Gastroenterology 1995;108:600-9.

30 Jen J, Powell SM, Papadopoulos N, et al. Molecular determinants of dysplasia in colorectal lesions. Cancer Res 1994;54:5523-6.

31 McLellan EA, Bird RP. Aberrant crypts: potential preneoplastic lesions in the murine colon. Cancer Res 1988;48: 6187-92.

32 Pretlow TP, Barrow BJ, Ashton WS, et al. Aberrant crypts: putative preneoplastic foci in human colonic mucosa. Cancer Res 1991;51:1564-7.

33 Takayama T, Katsuki S, Takahashi Y, et al. Aberrant crypt foci of the colon as precursors of adenoma and cancer. $N$ Engl f Med 1998;339:1277-84.

34 Barnes CJ, Hardman WE, Cameron IL, et al. Aspirin, but not sodium salicylate, indomethacin, or nabumetone,
reversibly suppresses 1,2-dimethylhydrazine-induced colonic aberrant crypt foci in rats. Dig Dis Sci 1997;42:920-6.

35 Young GP, McIntyre A, Albert V, et al. Wheat bran suppresses potato starch-potentiated colorectal tumorigenesis at the aberrant crypt stage in a rat model. Gastroenterology 1996;110:508-14.

36 Hendrickse CW, Keighley MRB, Neoptolemos JP. Dietary -3 fats reduce proliferation and tumour yields at colore tal anastomosis in rats. Gastroenterology 1995;109:431-9. 
37 British Nutrition Foundation Task Force. Unsaturated fatty acids and cancer. In: Unsaturated fatty acids. Nutritional and physiological significance. London: Chapman and Hall, 1992:120-8

38 Bartram HP, Gostner A, Reddy BS, et al. Missing anti-proliferative effect of fish oil on rectal epithelium in healthy volunteers consuming a high-fat diet: potential role of the n3:n6 fatty acid ratio. Eur $\mathcal{F}$ Cancer Prev 1995;4: 231-7.

39 Rao CV, Newmark HL, Reddy BS. Chemopreventive effect of squalene on colon cancer. Carcinogenesis 1998;19:287-90.

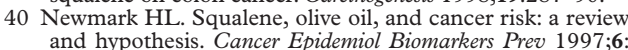
1101-3.

41 Rao CV, Simi B, Wynn TT, et al. Modulating effect of amount and types of dietary fat on colonic mucosal phospholipase $\mathrm{A}_{2}$, phosphatidylinositol-specific phospholiduring different stages of colon tumour promotion in male F344 rats. Cancer Res 1996;56:532-7.

42 Donowitz M. Arachidonic acid metabolites and their role in inflammatory bowel disease. An update requiring addition of a pathway. Gastroenterology 1985;88:580-7.

43 Zipser RD, Laffi G. Prostaglandins, thromboxanes and leukotrienes in clinical medicine. West f Med 1985;143:48597.

44 Rigas B. Eicosanoids and the gastrointestinal tract: promising but not verdict yet. Am F Gastroenterol 1986;81 218-21.

45 Lauritsen $\mathrm{K}$, Laursen LS, Bukhave $\mathrm{K}$, et al. Inflammatory intermediaries in inflammatory bowel disease. Int $\mathscr{f}$ Colorectal Dis 1989;4:75-90.

46 Rampton DS, Sladen GE, Youlten LJF. Rectal mucosal protaglandin $\mathrm{E}_{2}$ release and its relation to disease activity, electrical potential difference, and treatment in ulcerative colitis. Gut 1980;21:591-6.

47 Qiao L, Kozoni V, Tsioulias GJ, et al. Selected eicosanoids increase the proliferation rate of human colon carcinoma
lines and mouse colonocytes in vivo. Biochim Biophys Acta lines and mouse colon $1258: 215-23$.

48 Sheng H, Shao J, Morrow JD, et al. Modulation of apoptosis and Bcl-2 expression by prostaglandin $\mathrm{E}_{2}$ in human colon cancer cells. Cancer Res 1998;58:362-6.
49 Bennet A, Civier A, Hensby CN, et al. Measurement of arachidonate and its metabolites extracted from human chidonate and its metabolites extracted from human 28:315-18.

50 Pugh S, Thomas GAO. Patients with adenomatous polyps and carcinomas have increased colonic mucosal prostaglandin $\mathrm{E}_{2}$. Gut 1994;35:675-8.

51 Tsai MH, Yu CL, Wei FS, et al. The effect of GTPase activating protein upon rats is inhibited by mitogenically responsive lipids. Science 1989;243:522-6.

52 Telang NT, Basu A, Kurihara H, et al. Modulation in the expression of murine mammary tumour virus, ras protooncogene and of alveolar hyperplasia by fatty acids in mouse mammary explant cultures. Anticancer Res 1988;8:971-6.

53 Singh J, Hamid R, Reddy BS. Dietary fat and colon cancer: modulating effect of types and amount of dietary fat on ras-p21 function during promotion and progression stages of colon cancer. Cancer Res 1997;57:253-8.

54 Fernandes G, Chandrasekar B, Luan X, et al. Modulation of antioxidant enzymes and programmed cell death by n3 antioxidant enzymes and programmed

55 Chang WL, Chapkin RS, Lupton JR. Fish oil blocks azoxymethane-induced rat colon tumorigenesis by increasing cell differentiation and apoptosis rather cell proliferation. F Nutr 1998;128:491-7.

56 Latham P, Lund EK, Johnson IT. Dietary n-3 PUFA increases the apoptotic response to 1,2-dimethylhydrazine, reduces mitosis and suppresses the induction of carcinogenesis in the rat colon. Carcinogenesis 1999;20:645-50.

57 Nelson R, Holian O. Effects of dietary fish oil and corn oil on protein kinase $\mathrm{C}$ distribution in the rat colon with and without 1,2 dimethylhydrazine treatment and in rat colonic adenocarcinoma. Anticancer Res 1991;11:157-60.

58 Jiang YH, Lupton JR, Chang WCL, et al. Dietary fat and fiber differentially alter intracellular second messengers during tumour development in rat colon. Carcinogenesis 1996;17:1227-33.

59 Reddy BS, Simi B, Patel N, et al. Effect of amount and types of dietary fat on intestinal bacterial $7 \alpha$-dehydroxylase and phosphatidylinositol-specific phospholipase $\mathrm{C}$ and colonic mucosal diacylglycerol kinase and PKC activities during mucosal diacylglycerol kinase and PKC activities during 1996;56:2314-20. 